\title{
REVISÃO \\ ACIDEZ DO SOLO E CALAGEM EM POMARES DE FRUTÍFERAS TROPICAIS ${ }^{1}$
}

\author{
WILLIAM NATALE 2 , DANILO EDUARDO ROZANE ${ }^{3}$, \\ LÉON ETIENNE PARENT ${ }^{4}$, SÉRGE-ÉTIENNE PARENT ${ }^{4}$
}

RESUMO - A produtividade agrícola nos trópicos é afetada, principalmente, pelos fatores ligados à acidez do solo ( $\mathrm{pH}$, saturação por bases, acidez potencial, disponibilidade de nutrientes). A calagem é uma prática bem conhecida para corrigir a acidez do solo em culturas anuais, ainda que não seja praticada com a regularidade necessária. Entretanto, em culturas perenes, a incorporação de corretivos é mais complexa, devido às características desse grupo de plantas e à carência de informações científicas sobre o assunto. Em condições de acidez, a calagem promove a neutralização do $\mathrm{Al}^{3+}$, a elevação do $\mathrm{pH}$ e o fornecimento de $\mathrm{Ca}$ e $\mathrm{Mg}$, possibilitando a proliferação de raízes, com reflexos positivos no crescimento da parte aérea das plantas. Contudo, devido à baixa solubilidade e à lenta movimentação do calcário ao longo do perfil do solo, há obrigatoriedade de se fazer distribuição uniforme e incorporação profunda, antecedendo a implantação do pomar, a fim de garantir o eficiente aproveitamento de água e de nutrientes contidos nessas camadas. A calagem deve ser considerada um investimento, pois seus benefícios perduram além de um ano ou de uma safra agrícola. Isso se deve ao efeito residual dos corretivos de acidez do solo, sendo o tempo de duração desse efeito dependente de vários fatores, entre os quais: condições edafoclimáticas, cultura, manejo da área e tipo de corretivo empregado. Em geral, partículas maiores de calcário têm efeito residual mais prolongado, sendo empregadas na implantação dos pomares. No entanto, a relação entre o tamanho da partícula e o efeito residual tem sido pouco pesquisada, devido à necessidade de estudos de longa duração. Em função das elevadas doses de adubos nitrogenados utilizadas nos pomares de altos rendimentos, a acidez do solo aumenta, como resultado do processo de nitrificação. Em pomares já implantados, o procedimento atualmente utilizado pelos produtores é a incorporação superficial do calcário na área. As recomendações talvez fossem outras, caso houvesse maior subsídio da pesquisa, tendo em vista os diversos problemas fitossanitários que podem ocorrer, direta ou indiretamente da prática da incorporação do corretivo, tais como redução do sistema radicular, ferimento das raízes e consequente risco de infecções, com disseminação de pragas e doenças no pomar. O objetivo desta revisão é apresentar os principais resultados de pesquisas sobre o assunto, mostrando os efeitos da calagem sobre a fertilidade do solo, a nutrição e a produtividade de frutíferas de grande importância econômica para o Brasil, bem como discutir a duração do efeito residual dos corretivos e a dose mais ecônomica a ser aplicada nos pomares de frutas em implantação e em produção.

Termos para Indexação: Corretivo de acidez, Calcário, Implantação de pomar.

\section{SOIL ACIDITY AND LIMING IN TROPICAL FRUIT ORCHARDS}

\begin{abstract}
Agricultural productivity in the tropics is affected first by soil acidity and related factors ( $\mathrm{pH}$, base saturation, potential acidity, nutrient availability). Liming is a well-known but irregularly used beneficial practice to correct soil acidity in annual cropping systems. For perennial crops such as fruit orchards, lime incorporation is more difficult to implement as a result of length of the rotation and lack of scientific support. The lime neutralizes exchangeable aluminum, increases $\mathrm{pH}$ and supplies $\mathrm{Ca}$ and $\mathrm{Mg}$ to the growing roots. Because lime moves slowly in the soil, it must be incorporated deeply and uniformly before establishing the orchard to enhance soil exploration by the root system. Compared to fertilizers and pesticides liming can impact soil properties during several consecutive seasons and its effect depends on soil type, contact with the soil as lime is incorporated, fruit species and liming material. In general, the effect of larger lime particles is long-lasting. In orchards, lime is applied before establishment using lime materials of varying grain sizes. However, the relationship between grain size and long-time effect has been little studied because long-time research is expensive. With increasing application of ammonium-based $\mathrm{N}$ fertilizers in high-yielding orchards, soil acidity increases as a result of nitrification. Farmers presently apply lime superficially to established orchards in absence of sufficient experimentation on possible damage to the root system, root infection, pest blooms and soil compaction. The aim of this chapter is to quantify the effect of liming experiments on soil fertility, mineral nutrition and yield of tropical orchards in Brazil during establishment and full production cycles and determine the economic lime rate optimum for a long-term effect.
\end{abstract}

Index Terms: Acidity Correction, Limestone, Deploying Orchard.

\footnotetext{
1(Trabalho 257-12). Recebido em: 14-09-2012. Aceito para publicação em: 06-12-2012.

${ }^{2}$ Unesp/FCAV, Câmpus Jaboticabal, Jaboticabal, SP, Brasil. Bolsista PQ do CNPq. E-mail: natale@fcav.unesp.br

${ }^{3}$ Unesp FCAV, Câmpus Registro, Registro-SP, Brasil. E-mail: danilorozane@registro.unesp.br

${ }^{4}$ Université Laval, Département des Sols et de Génie Agroalimentaire, Québec (Qc), Canadá G1V 0A6. E-mails: leon-etienne.parent@

fsaa.ulaval.ca, sergeetienneparent@gmail.com
} 


\section{INTRODUÇÃO}

A fruticultura brasileira ocupa uma superfície de 2,3 milhões de hectares, gera anualmente 41 milhões de toneladas de frutas, o que representa cerca de US\$ 10 bilhões, colocando o Brasil entre os maiores produtores mundiais.

Apesar dessa posição de destaque, os rendimentos das frutíferas permanecem insatisfatórios, quando comparados à de países nos quais a atividade tem tradição. Dentre os vários fatores que contribuem para esse quadro, pode-se salientar o mau uso das técnicas de manejo do solo, da planta e do ambiente.

Nas últimas décadas, em função do melhoramento genético, as frutíferas passaram a produzir mais e com qualidade superior, porém a exigência e a exportação em nutrientes, como esperado, também aumentaram. Por outro lado, os solos brasileiros são naturalmente ácidos e pobres em termos de fertilidade e/ou têm sido submetidos a constante exploração, conduzindo-os à exaustão. A acidez do solo é um dos fatores que mais interferem na produtividade agrícola, especialmente nas regiões tropicais do globo. A aplicação de corretivos em culturas anuais é técnica conhecida e tem sido usada pelos agricultores; entretanto, em culturas perenes como as frutíferas, a incorporação do calcário é mais complexa, devido às características desse grupo de plantas e à carência de informações científicas sobre o assunto. As plantas frutíferas, assim como todas as perenes, permanecem longos períodos explorando praticamente o mesmo volume de solo, razão pela qual o ambiente radicular, em especial com respeito à acidez, merece a máxima atenção. Apesar da indiscutível importância para a maioria das plantas frutíferas, são escassas as informações sobre a prática da calagem na fase de implantação, formação e produção dos pomares.

Tendo em vista o exposto, fica evidente a importância da correção da acidez do solo, bem como de pesquisas sobre o assunto para as culturas perenes, podendo-se inferir que um acompanhamento químico do ambiente radicular das plantas, em especial com a prática da calagem, pode-se traduzir em benefícios para a produtividade dos pomares e, em consequência, em lucro para os fruticultores.

\section{CONSIDERAÇÕES SOBRE A FRUTICULTURA E AS PLANTAS FRUTÍFERAS}

O Brasil apresenta características privilegiadas para o desenvolvimento da fruticultura. Essas condições favoráveis são importantes, não apenas pelo valor nutritivo das frutas, mas também pela perspectiva que representa no incremento da produção agrícola, na ampliação da atividade agroindustrial e no potencial de exportações. Além disso, o cultivo de espécies perenes, como são a maioria das plantas frutíferas, permite a ocupação de solos considerados inadequados à atividade agrícola convencional, contribuindo, assim, com um sistema mais conservacionista.

Desde há muito tempo, porém, há carência de informações sobre aspectos ligados ao manejo da fertilidade do solo, de insumos e da exigência nutricional das plantas frutíferas, impedindo que o Brasil se destaque nessa área do Agronegócio.

É importante lembrar que os pomares de frutas são explorações agrícolas de longo prazo, cujas raízes das plantas permanecem praticamente restritas ao mesmo volume de solo por vários anos. Assim, a calagem realizada de modo adequado afetará, positivamente, o desenvolvimento e o estado nutricional das plantas, tendo como consequência o uso racional de fertilizantes e a melhoria da relação benefício/custo por meio do incremento da produtividade. Em pomares em produção, as elevadas doses de adubos nitrogenados amoniacais aplicados numa área restrita (projeção da copa das árvores frutíferas), por repetidos ciclos da cultura, têm contribuído para agravar o problema da acidez do solo, necessitando de acompanhamento constante via análise química para fins de fertilidade.

A fruticultura é uma atividade importante na maioria das regiões brasileiras, encontrando, nos Latossolos e Argissolos, que são geralmente profundos e permeáveis, condições ideais para as plantas perenes, tendo em vista seu sistema radicular abrangente e bastante desenvolvido. Entretanto, esses solos apresentam forte reação ácida e são pobres em nutrientes, necessitando, assim, de calagem e adubação.

Sabe-se que as raízes não se desenvolvem satisfatoriamente em solos muito ácidos. Entre os fatores da acidez, a toxicidade de alumínio e a deficiência de cálcio têm sido apontadas como as mais relevantes restrições ao crescimento radicular. No que diz respeito à correção da acidez da subsuperfície, com a aplicação de calcário na superfície do solo do pomar, sem incorporação, as pesquisas têm mostrado baixa movimentação do corretivo para camadas mais profundas e esse caminhamento no perfil depende da dose de corretivo aplicada, do tempo decorrido e da adubação.

$\mathrm{O}$ conhecimento e o manejo adequado da fertilidade do solo e da nutrição de plantas, especialmente no caso da fruticultura, são fundamentais, dada a influência que esses fatores de produção exercem sobre aspectos ligados à qualidade dos frutos, como cor, sabor, tamanho, aroma, aparência, etc. $\mathrm{O}$ aten- 
dimento das exigências nutricionais representa para as frutíferas um dos aspectos mais importantes para alcançar sucesso nessa atividade, pois, além de afetar a produtividade e a qualidade, a adequada nutrição influi no crescimento vegetal, na tolerância a pragas e doenças, bem como no armazenamento das colheitas. De um lado, a demanda desse grupo de plantas por elementos minerais é relativamente elevada e, de outro, há uma pobreza acentuada nos solos tropicais nos quais as mesmas são normalmente cultivadas, o que torna imperativa a aplicação da quase totalidade dos nutrientes necessários ao seu pleno desenvolvimento. Desse modo, fatores ligados ao solo e à planta conduzem à utilização de quantidades elevadas de fertilizantes e corretivos (NATALE et al., 2007a) nos pomares, o que pressupõe competência técnica que compense economicamente o uso desses insumos.

As informações sobre os efeitos da calagem no desenvolvimento e no estado nutricional das plantas frutíferas são escassas na literatura, embora haja amplo reconhecimento científico e técnico sobre a importância da correção da acidez. É compreensível, porém, que as culturas perenes não reajam à calagem e à adubação da mesma maneira que as culturas anuais. As razões são muitas, variadas e bem conhecidas:

- As raízes das plantas perenes, como as frutíferas, exploram um grande volume de solo, que aumenta com a idade das plantas, e conhece-se muito pouco sobre as reservas nutricionais das camadas de solo mais profundas.

- A planta perene como um todo (raízes, ramos, tronco e folhas) constitui um imenso reservatório de nutrientes. Em função disso, a árvore não demonstra, de modo imediato, as carências nutricionais do meio no qual está desenvolvendo- se. Assim, essas plantas reagem mais lentamente à aplicação de insumos.

- As podas constantes, a que normalmente são submetidas as plantas frutíferas, complicam o problema da calagem e da adubação. Restringindo-se o desenvolvimento vegetativo, prejudica-se a exteriorização dos resultados que se pode obter em consequência de melhor nutrição da planta. Entretanto, em muitos casos, a poda é imprescindível, pois é importante lembrar que a "fome de luz" é tão prejudicial quanto a "fome de nutrientes".

- A calagem e a adubação do pomar têm importância não somente para a frutificação em curso, mas também para a colheita futura, visto que os insumos aplicados no pomar servirão para: nutrir a produção pendente; formar novos ramos frutíferos para a colheita futura; constituir as reservas de elementos nas raízes e na parte aérea para as próximas frutificações.
Durante muito tempo, algumas frutíferas, em especial aquelas nativas das regiões tropicais, como a goiabeira e a caramboleira, foram consideradas plantas rústicas, razão pela qual se pensava que seu desenvolvimento era independente das condições edafoclimáticas, como se pensa hoje, ainda, das pastagens. Porém, não é possível imaginar que um solo possa ser explorado por uma cultura indefinidamente, sem fazer qualquer restituição de nutrientes ou correção de acidez. Mesmo assim, devido às características das plantas frutíferas perenes, as dificuldades de experimentação com essas culturas desencorajam pesquisas e pesquisadores.

\section{ACIDEZ DO SOLO E CALAGEM}

Dentre os fatores ambientais do solo, os ligados à acidez ( $\mathrm{pH}$, saturação por bases, acidez potencial e solubilidade de nutrientes) são os que mais interferem na produtividade agrícola, especialmente nas regiões tropicais (SANCHES; SALINAS, 1983).

De acordo com Malavolta (2006), a baixa fertilidade encontrada nos solos ácidos está associada, em grande parte, à pobreza em bases trocáveis e ao excesso de alumínio e manganês. Além disso, o uso constante de fertilizantes que acidificam o solo agrava o problema, se um programa bem planejado de calagem não for implementado.

Em função da pobreza em bases do material de origem, existem solos que são naturalmente ácidos. Outros solos sofreram processos que favoreceram as perdas de elementos como potássio, cálcio e magnésio, tornando-se ácidos. Em qualquer dos casos, o processo de acidificação tem início ou acentua- se, devido à remoção de cátions trocáveis da superfície dos coloides, através da: $a$ ) água da chuva; $b$ ) decomposição de minerais de argila; $c$ ) troca iônica das raízes; $d$ ) decomposição da matéria orgânica; $e$ ) adição de fertilizantes nitrogenados.

A calagem, prática reconhecidamente benéfica em condições de solo ácido, porém, nem sempre é realizada, ou o é de modo inadequado e, portanto, ineficaz. A aplicação de calcário promove a elevação do $\mathrm{pH}$, a neutralização do alumínio tóxico, fornece cálcio e magnésio, propicia maior desenvolvimento do sistema radicular das plantas, melhorando a eficiência de uso dos nutrientes e da água que estão no solo (RAIJ, 2011).

Entre os recursos minerais brasileiros, o calcário encontra-se em primeiro lugar, ocupando posição privilegiada, cujas reservas medidas são de 53 bilhões de toneladas, bem distribuídas pelo território nacional, e de boa qualidade.

Em função de sua abundância e qualidade, 
pode-se considerar que o calcário é um insumo agrícola relativamente barato. Entretanto, apesar do binômio "abundância de rocha calcária" x "necessidade de calagem", a interação entre esses dois fatores não ocorre com a intensidade necessária (MALAVOLTA, 2006).

A aplicação de corretivos de acidez em culturas anuais, com incorporação homogênea ao solo, é praticada comumente pelos agricultores, ainda que não com a regularidade devida. Por outro lado, em culturas perenes, a incorporação de corretivos de acidez é mais complexa, devido às características intrínsecas dessas plantas e à falta de informações científicas e tecnológicas (QUAGGIO et al., 2000). É o caso, por exemplo, da maioria dos pomares de frutas no Brasil.

É importante lembrar a necessidade de incorporar muito bem o calcário na implantação de culturas perenes, já que aplicações superficiais atuam lentamente nas camadas mais profundas, e um solo mal corrigido no início comprometerá a produtividade por muito tempo. A incorporação homogênea do calcário permite maior contato entre o corretivo e as fontes de acidez, resultando num efeito mais rápido, permitindo a proliferação de raízes e o eficiente aproveitamento da água e dos nutrientes contidos na camada corrigida.

A importância do sistema radicular das plantas é obvia, visto existir uma estreita dependência entre o desenvolvimento das raízes e a formação da parte aérea. O maior ou menor êxito da aplicação de calcário e fertilizantes depende, por sua vez, da natureza do sistema radicular e do volume de solo efetivamente explorado pela cultura. Assim, corrigir a acidez do solo é o modo mais eficiente e barato de eliminar as barreiras químicas ao pleno desenvolvimento das raízes e, em consequência, da planta (RAIJ, 2011).

Diferentemente de outros insumos agrícolas, como fertilizantes, herbicidas e inseticidas, o calcário pode ser considerado um investimento, visto que seus benefícios perduram por mais de uma safra. Isso se explica devido à baixa solubilidade dos materiais corretivos comuns e pela variabilidade de partículas que compõem os calcários, o que lhes confere diferentes capacidades de neutralizar a acidez ao longo do tempo. Desse modo, dois fatores devem ser considerados: a rapidez com que a acidez é corrigida, e o tempo de duração dos efeitos da calagem. As partículas mais finas promovem rápida correção da acidez, e esse efeito perdurará pela ação das partículas menos finas, devido à sua solubilização mais lenta. Pode-se inferir, pois, que o calcário mais eficiente é aquele que promove a mais rápida correção da acidez e que tem o maior efeito residual. Essa eficiência é conseguida quando um material calcário é composto por partículas de vários tamanhos (NATALE et al., 2007b).

Assim, em razão do efeito residual dos calcários, um material aplicado ao solo na implantação de um pomar de frutíferas pode manter a acidez dentro de limites aceitáveis pelas plantas por certo tempo. Entretanto, determinar qual o efeito residual da calagem no momento da implantação do pomar é assunto muito pouco estudado, seja pelas dificuldades experimentais, seja pelo tempo necessário para alcançar resultados satisfatórios, o que justifica a escassez de pesquisas sobre essa prática agrícola em plantas frutíferas (NATALE et al., 2010).

Considerando essas informações, porém, pode-se justificar o uso de calcários mais grosseiros na implantação dos pomares de frutas, com incorporação homogênea ao solo, a fim de que o efeito residual se prolongue pelo maior tempo possível. Por outro lado, nos pomares adultos, deve-se aplicar o corretivo com a granulometria mais fina possível, na superfície, pois a incorporação dos materiais corretivos ao solo pode trazer problemas fitossanitários às plantas. Desse modo, materiais constituídos de partículas mais finas podem caminhar mais facilmente no perfil do solo, corrigindo a acidez das camadas subsuperficiais.

Considerando a perenidade e as condições de cultivo das frutíferas, o deslocamento das partículas de calcário no solo pode ocorrer devido a vários outros fatores, como, por exemplo, uma contribuição de natureza física, caminhando através dos canais deixados pela decomposição de raízes (PEARSON et al., 1962). Segundo Harter,Naidu (1995) e Aoyama (1996), outra explicação para o deslocamento no perfil seria a formação de pares entre bases $\left(\mathrm{Ca}^{2+} \mathrm{e} \mathrm{Mg}^{2+}\right) \mathrm{e}$ ácidos orgânicos ( $\mathrm{RO}^{-}$e $\mathrm{RCOO}^{-}$) de alta solubilidade e baixa massa molecular, que permitiria o carreamento desses pares para camadas mais profundas, além da formação de outros compostos, como $\mathrm{Ca}\left(\mathrm{HCO}_{3}\right)^{2} \mathrm{e}$ $\mathrm{Mg}\left(\mathrm{HCO}_{3}\right)^{2}$. A adubação nitrogenada, por sua vez, pode promover a formação de sais solúveis, como o nitrato de $\mathrm{Ca}$, que percola pelo movimento descendente da água no perfil do solo (BLEVINS et al., 1977). Segundo Natale et al. (2007b), é provável que a soma das contribuições de todos os processos seja mais importante que cada um deles individualmente. Finalmente, é importante ressaltar que o caminhamento das partículas depende da dose de corretivo empregada, do tempo decorrido após a aplicação, do tipo de solo, da adubação do pomar, da declividade do terreno e do tipo de cobertura vegetal. 


\section{AMOSTRAGEM DE SOLO E DE FOLHAS EM POMARES DE FRUTÍFERAS}

A maior parte do Brasil é constituída por solos tropicais, os quais são pobres do ponto de vista da fertilidade e normalmente apresentam reação ácida. Isso se deve, especialmente, ao processo de desgaste a que os mesmos foram submetidos durante o período de formação. Essa é, pois, uma das principais razões para que se faça calagem e adubação nas áreas exploradas pela agricultura. Outro aspecto que precisa ser considerado é que um País, com as dimensões do Brasil, tem características de clima e solo muito variadas, o que implica tratamento diferenciado dos pomares instalados em cada diferente local.

É importante ressaltar, ainda, que solos diferentes têm carências diferentes em nutrientes, bem como as plantas, que, por sua vez, têm exigências nutricionais completamente diferentes umas das outras. Assim, a única maneira segura de identificar qual o corretivo de acidez ou o adubo a ser utilizado em determinada localidade é através da análise de solo.

A análise de solo é uma ferramenta consagrada na agricultura, porém, para a maioria das frutíferas, além de conhecer a fertilidade do solo, há necessidade de se realizar a análise foliar, em virtude da perenidade, visto que esse grupo de plantas adquire certa estabilidade nutricional na fase adulta (MARSCHNER, 1995). Em função dessa estabilidade nas frutíferas, a diagnose foliar permite ajustes nos programas de adubação em tempo de não comprometer a safra do pomar no mesmo ano. Esse é um método preciso de acompanhar, juntamente com a análise de solo, os efeitos da calagem e da adubação. A fruticultura é uma atividade de longo prazo, na qual as plantas permanecem explorando praticamente o mesmo volume de solo por vários anos. Nessa situação, podem ocorrer impedimentos químicos (acidez) ou físicos (compactação do solo) que diminuem a eficiência das raízes na exploração do solo. Assim, o modo mais usual de saber se a planta está aproveitando os nutrientes aplicados (via fertilizante ou calcário), é fazendo um diagnóstico do estado nutricional, através da análise foliar.

A análise química é a forma mais fácil e prática de se avaliar a fertilidade do solo. Apesar disso, uma de suas etapas, a amostragem, é da máxima importância, podendo comprometer todo o processo. A amostragem de solo em culturas anuais é prática comum entre os produtores rurais. Em culturas perenes, como os pomares de frutas, é uma questão pouco estudada e que suscita muitas dúvidas. As indicações existentes recomendam amostrar a área que recebe os adubos; entretanto alguns trabalhos têm mostrado melhor correlação entre os teores foliares das frutíferas e aqueles determinados no solo da entrelinha dos pomares (NATALE et al., 2007b; NATALE et al., 2008). Porém, se forem retiradas amostras na área adubada e na entrelinha do pomar, qual análise seguir? Como interpretar ou correlacionar? E a profundidade de retirada da amostra? Por tudo isso, estas são dúvidas que persistem, cujas respostas não são fáceis. Até as pesquisas para tentar respondê-las não deverão ser de concepção simples, segundo Raij (2011).

$\mathrm{Na}$ implantação dos pomares de frutas, o procedimento de amostragem do solo é o mesmo usado para as culturas anuais, ou seja, amostrar toda área de forma representativa. Nos pomares em produção, é importante amostrar a região da projeção da copa das plantas, que é a área que normalmente concentra a maior parte das raízes e recebe os fertilizantes. Devem ser coletados, no final da safra, vinte pontos em cada talhão homogêneo (mesma cultivar, idade, produtividade, tipo de solo, manejo e adubação). Ao mesmo tempo, deve-se realizar amostragem da entrelinha dos pomares, especialmente para a correção da acidez, quando necessário, considerando que a pesquisa tem mostrado relações mais estreitas entre $\mathrm{Ca}$ e $\mathrm{Mg}$ da entrelinha e aquele presente nas folhas (NATALE et al., 2007a). A prática agrícola indica que a acidificação ocorre mais intensamente na projeção da copa das árvores, devido ao adubo nitrogenado amoniacal, à aplicação de resíduos orgânicos e ao acúmulo de material vegetal resultante das podas. Como consequência, via de regra, realiza-se aplicação de calcário mais frequentemente na projeção da copa, em faixas, do que na entrelinha do pomar.

Na maior parte do Brasil, o cálculo da dose de calcário é realizado pelo método da saturação por bases (RAIJ et al., 1997). A fórmula utilizada para estabelecer a quantidade de corretivo a aplicar é a que segue:

$$
N C\left(t h a^{-1}\right)=\frac{\left(V_{2}-V_{1}\right) \times C T C}{P R N T \times 10}
$$

em que:

$\mathrm{NC}$ é a necessidade de calcário, em $\mathrm{t} \mathrm{ha}{ }^{-1}$;

$\mathrm{V}_{2}$ é a saturação por bases ideal para a cultura;

$\mathrm{V}_{1}$ é a saturação por bases do solo;

CTC é a capacidade de troca de cátions do solo; 
PRNT é o Poder Relativo de Neutralização Total, que considera a quantidade de carbonatos presente no corretivo e a granulometria do material.

A camada de solo amostrada é a superficial, ou seja, 0-20 cm. Entretanto, as plantas frutíferas exploram um volume de solo bem maior, sendo importante conhecer a condição da camada subsuperficial, em especial com relação às concentrações de cálcio e alumínio. Isso permite realizar a gessagem, que neutraliza o Al tóxico e permite aumentos na concentração de $\mathrm{Ca}$ em profundidade, o que é fundamental para a proliferação do sistema radicular e a exploração do solo.

A gessagem é indicada, para as culturas em geral, quando a análise de solo da camada de 20-40 $\mathrm{cm}$ revelar concentrações de cálcio inferiores a 4 $\mathrm{mmol}_{\mathrm{c}} \mathrm{dm}^{-3}$ e/ou saturação por alumínio acima de $40 \%$. A necessidade de gesso é estimada de acordo com a seguinte equação (RAIJ et al., 1997):

$$
N G\left(k g h a^{-1}\right)=6 \times \text { argila }
$$

em que:

NG é a necessidade de gesso, dada em $\mathrm{kg} \mathrm{ha}^{-1}$;

Teor de argila dado em $\mathrm{g} \mathrm{kg}^{-1}$.

No caso da diagnose do estado nutricional, a amostragem das folhas também é a etapa mais importante, sendo aquela em que os erros são mais frequentes. Para cada cultura, existe uma forma correta de amostragem. Assim, o tipo de folha a ser coletada, bem como a época de amostragem são imprescindíveis para o sucesso do diagnóstico do estado nutricional. No caso de frutíferas, como a goiabeira, por exemplo, em cada planta deve-se coletar o terceiro par de folhas, a partir da extremidade do ramo, em número de 25 pares por talhão homogêneo, à época de pleno florescimento da cultura (NATALE et al., 2007a). Essas folhas devem ser encaminhadas imediatamente ao laboratório onde serão lavadas, secas, moídas e submetidas à análise. O passo seguinte é a interpretação dos resultados, baseada em pesquisas realizadas em condições de campo, em pomares de alta produtividade.

Em resumo, pode-se dizer que, quando utilizadas de modo correto, as análises de solo e de folhas permitem recomendações de calagem e adubação que melhoram a produtividade, a qualidade dos produtos colhidos e garantem excelente retorno econômico ao fruticultor.

\section{CALAGEM NA IMPLANTACAO E NA FORMAÇAO DOS POMARES DE FRUTAS}

A acidez do solo é um dos mais importantes fatores que limitam a produção em regiões tropicais. Assim, Natale et al. (2007b) realizaram um experimento com o objetivo de avaliar os efeitos da calagem na fertilidade do solo, na nutrição e na produtividade da goiabeira. O calcário foi aplicado ao solo em julho/ agosto de 1999 e, após quatro meses, foi implantado o pomar (dezembro/1999), utilizando-se de goiabeiras (cv. Paluma) propagadas a partir de estacas herbáceas. O corretivo foi aplicado manualmente, em toda a superfície do terreno, metade antes da incorporação com arado de aivecas e a outra metade aplicada e depois incorporada com grade aradora, ambos os implementos abrangendo a camada de $0-30 \mathrm{~cm}$. $\mathrm{O}$ solo era um Latossolo Vermelho distrófico ( $\mathrm{V}=$ $26 \%$ na camada de $0-20 \mathrm{~cm}$ ). As doses de calcário empregadas foram: $0 ; 1,85 ; 3,71 ; 5,56 \mathrm{e} 7,41 \mathrm{t} \mathrm{ha}^{-1}$. Durante 78 meses após aplicação do corretivo, foram realizadas análises químicas de solo. Foi feita avaliação do estado nutricional e da produtividade das goiabeiras durante cinco safras agrícolas. A calagem promoveu alteração nos atributos químicos do solo ligados à acidez, elevando o $\mathrm{pH}, \mathrm{Ca}, \mathrm{Mg}$, soma de bases (SB) e saturação por bases (V) e diminuindo a acidez potencial $(\mathrm{H}+\mathrm{Al})$, até $60 \mathrm{~cm}$.

Observou-se incremento na produção acumulada de frutos (safras de 2002-2006), em função da saturação por bases na camada superficial do solo do pomar, tanto na entrelinha como na linha das goiabeiras. As maiores produções acumuladas de frutos foram alcançadas quando $\mathrm{V}$ estava próximo de $50 \%$ na linha da cultura e de $65 \%$ na entrelinha do pomar.

Nos primeiros anos após a implantação do pomar, verificou-se boa correlação entre os teores foliares de $\mathrm{Ca}$ e as concentrações do elemento no solo, tanto na entrelinha como na linha de plantio (Tabela 1). Entretanto, nos anos de 2004 e 2005, a correlação foi significativa apenas com as concentrações do elemento na entrelinha. De maneira geral, o mesmo ocorreu para o $\mathrm{Mg}$, observando-se relações mais estreitas do $\mathrm{Mg}$ nas folhas com aquele determinado na entrelinha do pomar. Isso pode indicar que, com o esgotamento dessas bases na linha de plantio, as raízes das goiabeiras absorveram os nutrientes de maneira mais efetiva na entrelinha da cultura, enfatizando a importância da calagem em área total.

Houve incremento da produtividade no período experimental (2002 a 2006), bem como da produção acumulada de goiabas, em função do aumento das doses de calcário, observando-se bom ajuste dos dados aos modelos linear e quadrático. 
O fornecimento de cálcio e magnésio, via corretivos de acidez, é uma vantagem adicional da aplicação dos calcários comuns, tendo em vista a elevação das concentrações desses macronutrientes no solo e, consequentemente, na frutífera. Desse modo, os teores foliares de cálcio e magnésio aumentaram nas goiabeiras, em função do incremento das doses de calcário aplicadas. Observou-se efeito quadrático entre a produção acumulada de frutos e os teores foliares de $\mathrm{Ca}$ e $\mathrm{Mg}$ na frutífera.

A relação $\mathrm{Ca} / \mathrm{Mg}$ nas folhas das goiabeiras mostrou, por outro lado, que valores muito estreitos são prejudiciais à produção acumulada de frutos, obtendo-se maiores rendimentos quando a relação está próxima de 4:1.

A aplicação de calcário em solos ácidos promove maior desenvolvimento do sistema radicular das plantas e, consequentemente, melhora a absorção de água e nutrientes. A determinação da concentração de cálcio no solo é um indicativo do potencial de crescimento do sistema radicular das frutíferas, especialmente nas fases de implantação e formação do pomar, e em situações em que o Ca se encontra em quantidades pequenas. Prado e Natale (2004) avaliaram os efeitos da aplicação de calcário ao solo, sobre o desenvolvimento do sistema radicular e sobre a nutrição de cálcio em goiabeiras cultivadas em um Latossolo Vermelho distrófico ácido. Analisaram-se amostras de solo coletadas em quatro pontos equidistantes, a $75 \mathrm{~cm}$ do tronco das plantas, nas camadas de 0-20 e 20-40 cm de profundidade, de parcelas que receberam zero; 3,7 e 7,4 tha-1 de corretivo de acidez. O calcário foi aplicado em pré-plantio, incorporado com arado de aivecas e grade aradora, na camada de 0-30 cm de profundidade. Aos 42 meses após a incorporação do calcário (terceiro ano de cultivo das goiabeiras), realizou-se a amostragem das raízes com trado cilíndrico serrilhado para a avaliação da matéria seca e do teor de cálcio radicular. A calagem promoveu a correção da acidez do solo, aumentando a saturação por bases, com consequente incremento da disponibilidade e absorção de cálcio pelas plantas, proporcionando maior desenvolvimento do sistema radicular das goiabeiras. Concentrações de cálcio próximas de $30 \mathrm{mmol}_{\mathrm{c}} \mathrm{dm}^{-3}$ no solo e teor desse nutriente de 7,5 $\mathrm{g} \mathrm{kg}^{-1}$ nas raízes estiveram associados ao maior crescimento radicular da frutífera.

Salienta-se, ainda, que a calagem, ao elevar as quantidades de cálcio e magnésio no solo e na planta, pode afetar a qualidade dos frutos. Neste sentido, Prado et al. (2005) estudaram os efeitos da calagem na qualidade de frutos de goiabeiras, observando que essa prática não afetou as características físicas dos frutos, como peso, diâmetro transversal, comprimento, peso de polpa e porcentagem de polpa. Entretanto, a aplicação de calcário proporcionou aumento linear dos teores de cálcio nas folhas e nos frutos da goiabeira, promovendo menor perda de peso de matéria fresca e maior firmeza dos frutos, estando associados aos teores de $\mathrm{Ca}$ nos frutos próximos a $0,99 \mathrm{~g} \mathrm{~kg}^{-1}$. Assim, a nutrição adequada da planta em cálcio melhorou a qualidade dos frutos, com benefícios crescentes para a pós-colheita, ao longo do período de armazenamento.

Estes efeitos benéficos do $\mathrm{Ca}$ na qualidade dos frutos podem ser explicados pelo papel deste elemento na nutrição das plantas. Considerando isso, Natale et al. (2005) observaram que, nos frutos de goiabeiras que receberam a aplicação de cálcio (na forma de calcário), as paredes celulares e as lamelas médias estavam bem definidas e estruturadas, mantendo as células unidas. Já nas plantas que não receberam calagem, os frutos apresentavam as paredes celulares desestruturadas e com desorganização da lamela média. Os autores concluíram que a aplicação de cálcio, na forma de calcário, mostrou-se efetiva na organização subcelular dos frutos da goiabeira, contribuindo para a integridade dos mesmos.

Estudos que apontam os efeitos da calagem sobre variáveis biométricas das plantas são escassos na literatura. Com esse intuito, Souza et al. (2009) desenvolveram um experimento, em condições de campo, empregando doses de calcário e avaliando seu efeito sobre o diâmetro do tronco, a altura e o volume da copa, a partir da implantação de um pomar de goiabeiras 'Paluma'. Os tratamentos consistiram em doses crescentes de corretivo, calculadas para a camada de $0-30 \mathrm{~cm}$, como segue: $\mathrm{D}_{0}=$ zero de calcário; $\mathrm{D}_{1}=$ metade da dose para elevar $\mathrm{V}=70 \%$; $\mathrm{D}_{2}=\mathrm{a}$ dose para elevar $\mathrm{V}=70 \% ; \mathrm{D}_{3}=1,5 \mathrm{vez}$ a dose para elevar $\mathrm{V}=70 \%$; e $\mathrm{D}_{4}=2$ vezes a dose para elevar $\mathrm{V}=70 \%$. As avaliações foram realizadas durante sete anos, iniciando-se com a implantação do pomar em 1999/2000 até 2005/2006. As doses de calcário proporcionaram, ao longo dos anos, ganhos no diâmetro do tronco, na altura e no volume da copa das goiabeiras. A pesquisa permitiu que se constatasse a importância da correção da acidez do solo e os benefícios da aplicação do calcário sobre variáveis biométricas das goiabeiras.

Apesar de ter seu centro de origem nas regiões tropicais, há indicações na literatura de que a caramboleira é responsiva à correção da acidez do solo e à aplicação de fertilizantes. Prado e Natale (2004), avaliando plantas com três anos de idade, em condições de campo, constataram que o acúmulo de matéria seca do sistema radicular dessa Oxalidaceae é beneficiado pela aplicação de calcário, refletindo 
na absorção de nutrientes e no desenvolvimento das plantas.

Devido à baixa solubilidade dos materiais corretivos da acidez, a incorporação profunda e homogênea do calcário em toda a área, antecedendo o plantio das mudas, é prática conhecida e utilizada pelos fruticultores, visto ser a última oportunidade de mobilizar o solo, partindo da premissa de que não é aconselhável revolvê-lo em pomares já implantados, nem tampouco aplicar calcário na cova de plantio, especialmente junto com fontes de fósforo.

Apesar da reconhecida necessidade e importância da correção da acidez, praticamente inexistem estudos avaliando o efeito residual dessa prática agrícola em pomar de caramboleiras. Assim, Natale et al. (2008) estudaram, no período de 1999 a 2006, o efeito da aplicação de calcário na cultura da carambola. Os autores observaram que a aplicação do corretivo promoveu alterações significativas no $\mathrm{pH}$ do solo, acidez potencial $(\mathrm{H}+\mathrm{Al})$, soma de bases, saturação por bases e nas concentrações de $\mathrm{Ca}$ e $\mathrm{Mg}$, nas profundidades de 0-20, 20-30, 30-40 e 40-60 cm. Além disso, ocorreu incremento linear do $\mathrm{pH}, \mathrm{Ca}, \mathrm{Mg}, \mathrm{SB}$ e V\% e decréscimo, também com ajuste linear do $(\mathrm{H}+\mathrm{Al})$, em função das doses de calcário, tanto na entrelinha como na linha do pomar de caramboleiras, em todas as profundidades amostradas, sendo as alterações mais expressivas na região de incorporação do corretivo $(0-30 \mathrm{~cm})$, o que era esperado devido a sua baixa mobilidade.

As produções acumuladas de frutos das caramboleiras nas safras de 2002-2006, em função da aplicação do corretivo de acidez, estão apresentadas na Figura 1, podendo-se observar que a saturação por bases na entrelinha se manteve com valores mais altos ao longo do experimento, em relação à projeção da copa das caramboleiras. Tal comportamento era esperado, dado que o manejo do pomar impõe a aplicação localizada de elevadas doses de fertilizantes nitrogenados amoniacais, que têm como característica a acidificação do solo durante o processo de nitrificação (MALAVOLTA, 2006). Não se pode desprezar, também, a ação das raízes das caramboleiras sobre o solo, absorvendo Ca e Mg para sua nutrição e exsudando $\mathrm{H}^{+}$. Convém ressaltar que, no pomar, foi realizada irrigação localizada, o que, de todo modo, contribui para alterações nas taxas de amonificação, nitrificação e desnitrificação, atributos estes que, de acordo com Miller e Cramer (2004), estão ligados à disponibilidade, à localização e às formas de $\mathrm{N}$ encontradas no perfil do solo. Isso é de fundamental importância, dada a alta mobilidade do nitrogênio, principalmente devido a sua baixa energia de ligação aos argilominerais e à matéria orgânica, contribuindo para a lixiviação (RAIJ, 2011).

Observa-se, ainda, na Figura 1, que houve incremento da produção acumulada de frutos (safras de 2002 a 2006), em função da saturação por bases do solo na camada de $0-20 \mathrm{~cm}$, tanto na linha como na entrelinha do pomar. Assim, 78 meses após a implantação do experimento para a correção da acidez do solo, observou-se que a máxima produção de frutos foi obtida com $\mathrm{pH}$ entre 4,6 e 5,0, quando a saturação por bases atingiu $40 \%$ e $53 \%$, e a produtividade alcançou 124 e $118 \mathrm{t} \mathrm{ha}^{-1}$, na linha e na entrelinha da caramboleira, estando os teores foliares de $\mathrm{Ca}$ e $\mathrm{Mg}$ em 7,6 e 4,0 $\mathrm{g} \mathrm{kg}^{-1}$, respectivamente (NATALE et al., 2008).

A Figura 2 mostra as diferenças de produção acumulada de carambolas nas safras de 2002 a 2006. Observa-se, como esperado, que a quantidade acumulada de frutos aumenta, à medida que mais safras são adicionadas, independentemente da dose de calcário empregada. Isso é resultado, também, do crescimento das caramboleiras em altura, área foliar e capacidade produtiva que, com o passar dos anos, aumentou, pois o pomar estava em início de formação.

Através da Figura 3, pode-se observar que a produção acumulada de frutos aumenta com o passar das safras, independentemente da dose de corretivo aplicada. Há, porém, uma nítida diferença na produção acumulada com o passar do tempo. É importante destacar, também, que mesmo passados sete anos, as plantas das parcelas-testemunha (dose zero de calcário) ainda produziam quantidades apreciáveis de frutos, demonstrando a excepcional capacidade da caramboleira para se desenvolver em condições adversas.

Em uma abordagem sobre o aspecto econômico da calagem, Natale et al. (2011) observaram que as produções acumuladas de carambolas, empregando-se as diferentes doses economicamente viáveis de calcário, coincidiram com as produções máximas possíveis (Tabela 2). Isso ocorreu devido à alta capacidade produtiva desta frutífera, bem como ao elevado preço médio da carambola praticado no mercado.

A porcentagem da produção de frutos obtida com a dose mais econômica, em relação à produção máxima, seria de 100\%. Desse modo, a aplicação da dose econômica permitiu economia de calcário, sem perda significativa da produção de frutos. Assim, é possível concluir que as caramboleiras responderam positiva e economicamente à aplicação de calcário, elevando a produção de frutos até a dose considerada adequada e recomendada por Natale et al. (2008).

As principais áreas de cultivo de caramboleira no Brasil estão localizadas em regiões cujos solos 
são caracterizados pela acidez e baixa saturação por bases, o que limita o desenvolvimento normal das plantas, refletindo na produção. Assim, Hernandes et al. (2010) avaliaram os efeitos da aplicação de doses crescentes de calcário ao solo sobre o diâmetro do tronco, o volume da copa e a altura de caramboleiras. O experimento foi realizado no Estado de São Paulo, em um Latossolo Vermelho, no período de agosto/1999 a julho/2006. As doses de calcário empregadas foram: zero; 1,$85 ; 3,71 ; 5,56 \mathrm{e} 7,41 \mathrm{t} \mathrm{ha}^{-1}$. Foram realizadas análises químicas do solo para fins de fertilidade e avaliações de variáveis biométricas, como diâmetro do tronco, altura e volume da copa das caramboleiras, durante cinco safras agrícolas. A neutralização da acidez do solo proporcionou incremento das variáveis biométricas da frutífera durante todo o período experimental. A calagem promoveu aumento no diâmetro do tronco, na altura e no volume da copa das caramboleiras. Os componentes do calcário, cálcio e magnésio, influenciaram positivamente no desenvolvimento das caramboleiras.

\section{CALAGEM PARA POMARES DE FRUTAS EM PRODUÇÃO}

A baixa solubilidade da maioria dos corretivos de acidez limita a mobilidade desses materiais no perfil do solo, obrigando sua incorporação para se obter um efeito benéfico na zona explorada pelas raízes. Nos pomares de frutíferas já implantados, o procedimento indicado pelos boletins oficiais no Brasil é uma leve incorporação do calcário nas entrelinhas (RAIJ et al., 1997). Entretanto, é provável que a recomendação fosse outra, caso houvesse maior subsídio da pesquisa, considerando os diversos problemas fitossanitários que podem ocorrer devido à prática da incorporação dos corretivos, tais como:ferimentos e redução do volume de raízes, com consequente risco de infecções, disseminação de doenças no pomar, favorecimento da dispersão de pragas, em especial de ácaros, cochonilhas (GRAVENA, 1993) e nematoides, desestruturação e compactação do solo, fatores que podem refletir no rendimento das culturas.

Em pomares adultos, o calcário aplicado na superfície do solo, sem incorporação, neutralizará gradualmente a acidez em profundidade, devido ao movimento das partículas no perfil, numa taxa de 1 a $2 \mathrm{~cm}$ por ano, se as condições de umidade e drenagem forem adequadas (BROWN et al., 1956, citados por LIEROP, 1990). Desse modo, a calagem superficial, ainda que possível, requer tempo para produzir efeitos benéficos. Entretanto, a informação acima citada foi obtida em condições edafoclimáticas diferentes dos trópicos. As pesquisas têm mostrado que é possível aplicar o corretivo superficialmente, sem incorporação, obtendo-se resultados satisfatórios ao longo do tempo, conforme será relatado a seguir.

Com o objetivo de avaliar o efeito da calagem superficial sobre a fertilidade do solo e sobre a nutrição e produção da goiabeira, Corrêa et al. (2004) desenvolveram um experimento no campo, em pomar comercial instalado sobre Argissolo Vermelho-Amarelo, na maior região produtora de goiabas do Estado de São Paulo. Utilizou-se o delineamento em blocos casualizados, em esquema fatorial $2 \times 5$, com três repetições, sendo dois tipos de calcário (comum, com $\mathrm{PRNT}=80 \%$; e calcinado, com $\mathrm{PRNT}=131 \%$ ), aplicados em cinco doses [zero; 0,$5 ; 1 ; 1,5$ e 2 vezes a dose recomendada para elevar a saturação por bases (V) a 70\%], sem incorporação. De acordo com os resultados obtidos, a calagem superficial, com calcário comum ou calcário calcinado, reduziu a acidez do solo nas camadas de 0-10 e 10-20 cm, no pomar estabelecido de goiabeiras, de forma proporcional às doses aplicadas. Na camada de 10-20 cm, observou-se redução da acidez após 6 a 12 meses da calagem com o calcário calcinado e, após 24 meses da aplicação, com o calcário comum. A composição química das folhas e dos frutos, bem como a produtividade das goiabeiras não foram afetadas pelos tratamentos, atribuindo-se isso à perenidade das plantas, que necessitam de tempo para responder às alterações de manejo. Os autores concluíram que é possível a utilização da técnica da calagem superficial em pomares estabelecidos de goiabeiras para a correção da acidez, tanto da camada superficial, como da subsuperfície do solo; contudo, ressaltam serem necessários outros estudos para a determinação de critérios específicos para a cultura, bem como para a adequação das doses pelo método da saturação por bases a essa modalidade de calagem.

A laranja é a mais importante frutífera do Brasil, ocupando uma superfície de 850 mil hectares. O País é o maior produtor mundial, respondendo por $25 \%$ da produção dessa fruta. Isso significa que, de cada cinco copos de suco de laranja consumidos no mundo, três são produzidos no Brasil (NEVES et al., 2010). Considerando a importância da cultura de citros para o País, Silva et al. (2007) conduziram um experimento de campo, em um pomar adulto de laranjeira Pera, instalado sobre um Latossolo Vermelho. Empregaram-se cinco doses de calcário calcinado (PRNT=131\%), aplicado superficialmente, sem incorporação. Os efeitos dos tratamentos foram avaliados durante três anos, acompanhando-se a movimentação do corretivo no perfil do solo, aos $6 ; 12 ; 18 ; 24 ; 30$ e 36 meses após a calagem, e 
determinando-se as alterações nas propriedades químicas do solo, no estado nutricional e na produção de frutos. Os autores concluíram que a aplicação superficial de calcário calcinado alterou a saturação por bases $(\mathrm{V} \%)$, bem como o ambiente químico do solo nas camadas de $0-10 ; 10-20$ e $20-40 \mathrm{~cm}$. Pelos resultados obtidos, o período compreendido entre 12 e 18 meses foi aquele no qual ocorreu a máxima reação do calcário calcinado nas camadas subsuperficiais. O estado nutricional das plantas e a produção de laranjas foram alterados significativamente, sendo que a produtividade acumulada indica que a saturação por bases ideal para a cultura da laranja está em torno de 50\%. No mesmo estudo, Silva et al. (2009) avaliaram os efeitos das doses de corretivo sobre os teores foliares de manganês no pomar de laranjeiras. Constataram decréscimos significativos nos teores desse micronutriente, à medida que as doses de calcário aumentaram. Houve alta correlação entre a saturação por bases na camada de $10-20 \mathrm{~cm}$ e os teores foliares de $\mathrm{Mn}$. As maiores produtividades de frutos estiveram associadas aos níveis foliares entre 33 e 70 $\mathrm{mg}$ de $\mathrm{Mn} \mathrm{kg}^{-1}$. O experimento de calagem permitiu determinar, ainda, através dos métodos CND, DRIS e Chance Matemática, as faixas de teores de nutrientes adequados para a obtenção de alta produtividade em pomar de laranjeira Pera (CAMACHO et al., 2012).

Apesar da insuficiência de base científica, a experiência prática tem mostrado que, em pomares de frutas já implantados, não se deve permitir que o $\mathrm{pH}$ do solo e, consequentemente, a saturação por bases se reduzam drasticamente. Isso porque, torna-se muito difícil conseguir corrigir uma acidez elevada, nas camadas de solo exploradas pelas raízes nos pomares adultos, em espaço de tempo razoável. Assim, a estratégia nessas situações é aplicar anualmente pequenas doses de corretivo finamente moído (por exemplo, $1 \mathrm{t} \mathrm{ha}^{-1}$ ), a fim de corrigir a acidez, gradativamente, por meio da movimentação do calcário no perfil do solo, evitando uma forte acidez nos pomares em produção. Fica claro, porém, que a análise de solo continua imprescindível também nessa situação, e que pesquisas devem ser realizadas para determinar as doses mais adequadas, visto que o corretivo é aplicado na superfície, sem incorporação.

TABELA 1- Coeficientes de correlação entre o teor de cálcio e de magnésio do solo na camada de 0-20 cm da entrelinha e linha do pomar e os teores foliares de $\mathrm{Ca}$ e $\mathrm{Mg}$ das goiabeiras, nos diferentes anos de cultivo (os valores são médias de quatro repetições em cada ano).

\begin{tabular}{|c|c|c|c|c|c|c|c|c|c|c|}
\hline \multirow{3}{*}{$\begin{array}{l}\text { Nutriente } \\
\text { no solo }\end{array}$} & \multicolumn{10}{|c|}{ Nutriente na folha } \\
\hline & \multicolumn{2}{|c|}{2001} & \multicolumn{2}{|c|}{2002} & \multicolumn{2}{|c|}{2003} & \multicolumn{2}{|c|}{2004} & \multicolumn{2}{|c|}{2005} \\
\hline & $\mathrm{Ca}$ & $\mathrm{Mg}$ & $\mathrm{Ca}$ & $\mathrm{Mg}$ & $\mathrm{Ca}$ & $\mathrm{Mg}$ & $\mathrm{Ca}$ & $\mathrm{Mg}$ & $\mathrm{Ca}$ & $\mathrm{Mg}$ \\
\hline$\overline{\mathrm{Ca}(\mathrm{L})}$ & $0,91 *$ & & $0,99 * *$ & & $0,95^{*}$ & & $\mathrm{~ns}$ & & ns & \\
\hline $\mathrm{Ca}(\mathrm{E})$ & $0,94 *$ & & $0,96 * *$ & & $0,99 *$ & & $0,97 *$ & & $0,93 *$ & \\
\hline $\operatorname{Mg}(\mathrm{L})$ & & ns & & $0,79 *$ & & ns & & ns & & ns \\
\hline $\operatorname{Mg}(\mathrm{E})$ & & ns & & $0,92 *$ & & $0,97^{*}$ & & $0,81 *$ & & $0,84 *$ \\
\hline
\end{tabular}

E: entrelinha do pomar, L: linha de plantio das goiabeiras. ${ }^{*}, *$ e ns Significativo $p<0,01, p<0,05$ e não significativo, respectivamente.

TABELA 2- Dose econômica de calcário, calculada em função da produção acumulada de frutos da caramboleira e do custo do corretivo, para o período de 2002 a 2006.

\begin{tabular}{cccccc}
\hline $\begin{array}{c}\text { Produção } \\
\text { acumulada }\end{array}$ & $\begin{array}{c}\text { Dose } \\
\text { econômica }\end{array}$ & $\begin{array}{c}\text { Aumento de } \\
\text { produção }\end{array}$ & $\begin{array}{c}\text { Custo do } \\
\text { calcário }\end{array}$ & Lucro & Produção $^{1}$ \\
\hline & t ha $^{-1}$ & -------- & t de fruto por ha ---------- & $\%$ \\
2002 a 2003 & 4,5 & 8,4 & 0,3 & 8,1 & 100 \\
2002 a 2004 & 4,8 & 16,0 & 0,3 & 15,7 & 100 \\
2002 a 2005 & 5,3 & 28,8 & 0,3 & 28,5 & 100 \\
2002 a 2006 & 5,3 & 34,2 & 0,3 & 33,9 & 100 \\
\hline
\end{tabular}

${ }^{1}$ Porcentagem da produção de frutos obtida com a dose mais econômica, em relação à produção máxima. 


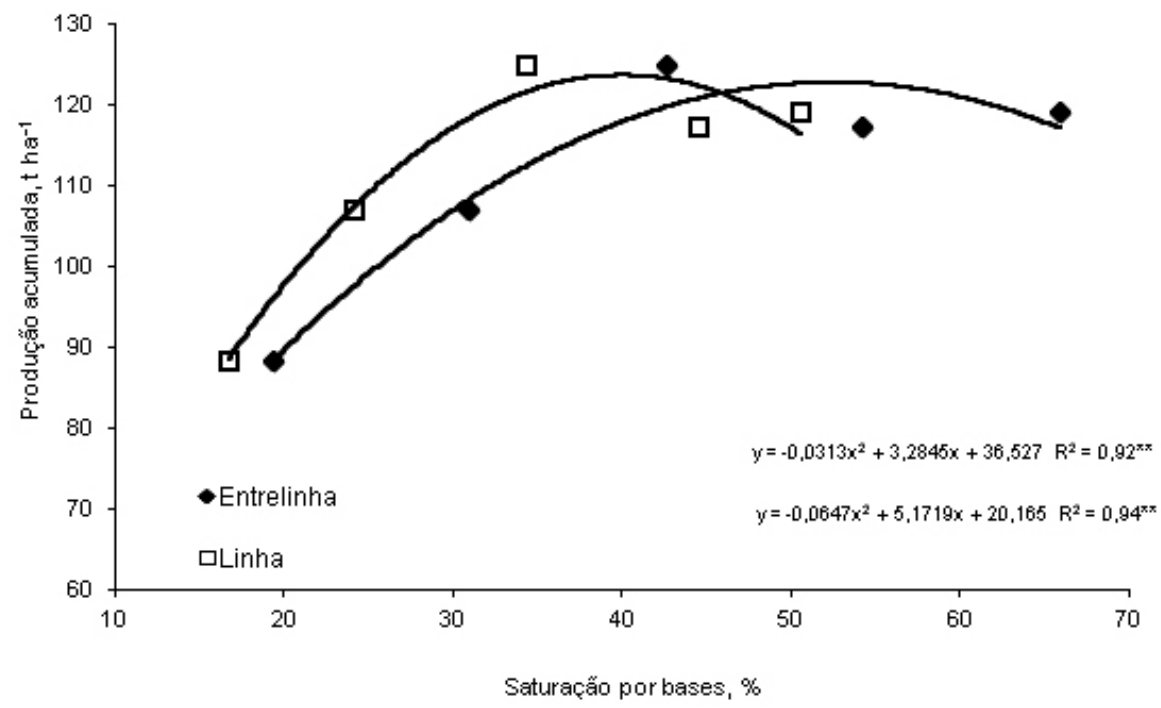

FIGURA 1- Relação entre a saturação por bases do solo, na camada de 0-20 cm, na entrelinha e na linha do pomar de caramboleiras (média de todas as amostragens) e a produção acumulada de frutos nos anos agrícolas de 2002 a 2006.

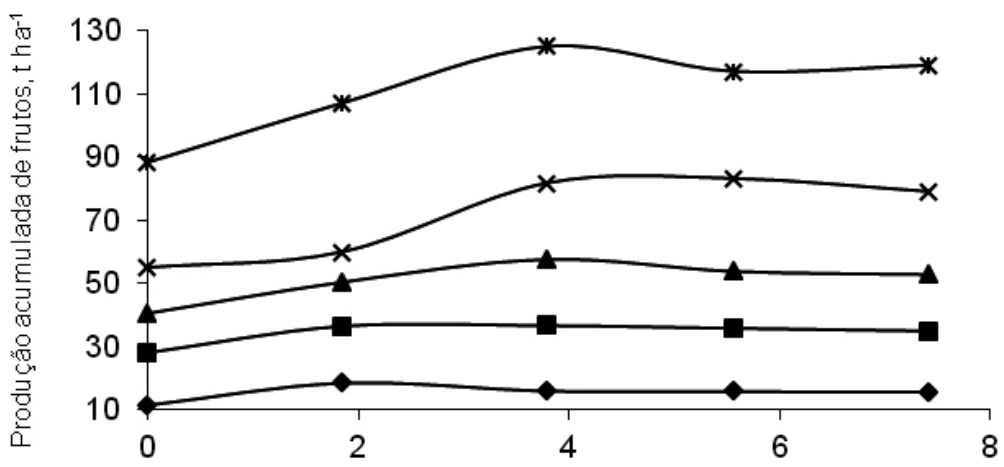

\section{Safras}

$\multimap-2002$

$\rightarrow-2002+03$

$\longrightarrow$ - 2002+03+04

$\longrightarrow-2002+03+04+05$

$\longrightarrow$ * $2002+03+04+05+06$

Dose de calcário aplicado em 1999, tha-1

FIGURA 2 - Produção acumulada de carambolas, em função das diferentes doses de calcário aplicadas em 1999.

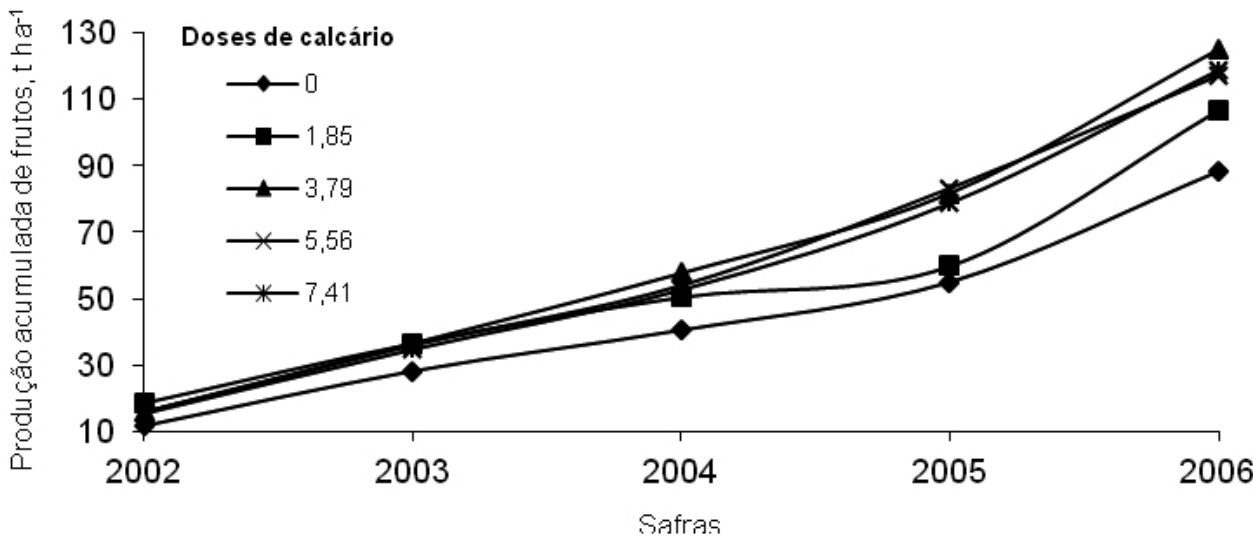

FIGURA 3 - Produção acumulada de carambolas, nas safras 2002 a 2006, em função das doses de calcário aplicadas em 1999. 


\section{REFERÊNCIAS}

AOYAMA, M. Fractionation of water-soluble organic substances formed during plant residue decomposition and high performance size exclusion chromatography of the fractions. Soil Science Plant Nutrition, Tokyo, v.42, p.21-30, 1996.

BLEVINS, R. L.; THOMAS, G. W.; CORNELUIS, P. L. Influence of no-tillage and nitrogen fertilization on certain soil properties after 5 years of continuous corn. Agronomy Journal, Madison, v.69, p.383386, 1977.

CAMACHO, M.A.; SILVEIRA, M. V.; CAMARGO, R. A.; NATALE, W. Faixas normais de nutrientes pelos métodos ChM, DRIS e CND e nível crítico pelo método de distribuição normal reduzida para laranjeira-Pera. Revista Brasileira de Ciência do Solo, Campinas, v.36, p.193-200, 2012.

CORREAA, M. C. M., NATALE, W., PRADO, R. M., BANZATTO, D. Liming to an adult guava tree orchard In: INTERNATIONAL SIMPOSIUM ON TROPICAL AND SUBTROPICAL FRUITS, 3., 2004, Fortaleza. Proceedings... Fortaleza: EmbrapaCNPAT, 2004. p. 215.

GRAVENA, S. Manejo integrado de pragas dos citros: adequação para manejo de solo. Laranja, Cordeirópolis, v.14. p.401-19, 1993.

HARTER, R. D.; NAIDU, R. Role of metal-organic complexation in metal sorption by soils. Advance in Agronomy, San Diego, v.55, p.219-263, 1995.

HERNANDES, A.; NATALE, W.; PRADO, R. de. M.; ROZANE, D. E.; ROMUALDO, L. M.; SOUZA, H. A. Calagem no crescimento e desenvolvimento da caramboleira. Revista Brasileira de Ciências Agrárias, Recife, v.5, p.170-176, 2010.

LIEROP, W. van. Soil $\mathrm{pH}$ and lime requirement determination. In: WESTERMAN, R.L. (Ed.). Soil testing and plant analysis. 3.ed. Madison: Soil Science Society of America, 1990. p.73-126.

MALAVOLTA, E. Manual de nutrição mineral de plantas. Piracicaba: Ceres, 2006. 638p.

MARSCHNER, H. Mineral nutrition higher plants. London: Academic Press, 1995. 674p.
MILLER, A. J.; CRAMER, M. D. Root nitrogen acquisition and assimilation. Plant and Soil, Dordrecht, v.274, p. 1-36, 2004.

NATALE, W.; PRADO, R. M.; MÔRO, F. V. Alterações anatômicas induzidas pelo cálcio na parede celular de frutos de goiabeira. Pesquisa Agropecuária Brasiliera, Brasília, v.40, n.12, p.1239-1242, 2005.

NATALE, W.; PRADO, R. M.; QUAGGIO, J. A.; MATTOS JUNIOR, D. Guava. In: CRISÒSTOMO, L.A.; NAUMOV, A.; JOHNSTON, A.E. (Org.). Fertilizing for high yield and quality tropical fruits of Brazil. Horgen: International Potash Institute, 2007a. v. 1, p.103-122.

NATALE, W.; PRADO, R. M.; ROZANE, D. E.; ROMUALDO, L. M. Efeitos da calagem na fertilidade do solo e na nutrição e produtividade da goiabeira. Revista Brasileira de Ciência do Solo, Viçosa, v. 31, n. 6, p. 1.475-1.485, 2007 b.

NATALE, W.; PRADO, R. M.; ROZANE, D. E.; ROMUALDO, L. M.; SOUZA, H.A.; HERNANDES, A. Resposta da caramboleira à calagem. Revista Brasileira de Fruticultura, Jaboticabal, v. 30, n. 4, p. 1136-1145, 2008.

NATALE, W; ROZANE, D. E.; PRADO, R. de M.; ROMUALDO, L. M.; SOUZA, H. A. de; HERNANDES, A. Viabilidade econômica do uso do calcário na implantação de pomar de goiabeiras. Ciência e Agrotecnologia, Lavras, v. 34, n. 3, p. 708-713, 2010

NATALE, W.; ROZANE, D. E.; PRADO, R. de M.; ROMUALDO, L. M.; SOUZA, H. A. de; HERNANDES, A. Dose de calcário economicamente viável em pomar de caramboleiras. Revista Brasileira de Fruticultura, Jaboticabal, v. 33, n. 4, p. 1294-1299, 2011.

NEVES, M. F.; TROMBIN, V. G.; MILAN, P.; LOPES, F. F.; CRESSONI, F.; KALAKI, R. O retrato da citricultura Brasileira. Ribeirão Preto: FEA/USP, 2010. 139p.

PEARSON, R. W.; ABRUNA, F.; VICE-CHANCES, J. Effect of lime and nitrogen applications on downward movements of calcium and magnesium in two humid soils of Puerto Rico. Soil Science, Baltimore, v.93, p.77-82, 1962. 
PRADO, R. M.; NATALE, W. A calagem na nutrição e no desenvolvimento do sistema radical da caramboleira. Revista de Ciências Agroveterinárias, Lages, v.3, n.1, p.3-8, 2004.

PRADO, R. M; NATALE, W.; SILVA, J. A. A. Liming and quality of guava fruit cultivated in Brasil. Scientia Horticulturae, Amsterdam, v. 104, n. 6, p.91-102, 2005.

QUAGgiO, J. A. Acidez e calagem em solos tropicais. Campinas: Instituto Agronômico, 2000. $111 \mathrm{p}$.

RAIJ, B. van. Fertilidade do solo e manejo de nutrientes. Piracicaba: IPNI, 2011. 420 p.

RAIJ, B. van; CANTARELLA, H; QUAGGIO, J. A.; FURLANI, A.M.C. (Ed.). Recomendações de adubação e calagem para o Estado de São Paulo. 2.ed. Campinas: Fundação IAC, 1997. 285 p. (Boletim Técnico, 100).
SANCHEZ, P. A.; SALINAS, J. G. Suelos acidos: estrategias para su manejo con bajos insumos en America Tropical. Bogotá: Sociedad Colombiana de la Ciencia del Suelo, 1983. 93p.

SILVA, M. A. C.; NATALE, W.; PRADO, R. M.; CHIBA, M. K. Liming and Manganese Foliar Levels in Orange. Journal of Plant Nutrition, New York, v.32, p.694-702, 2009.

SILVA, M. A. C.; NATALE, W.; PRADO, R. M.; CORRÊA, M. C. M.; STUCHI E. S.; ANDRIOLI, I. Aplicaçao Superficial de calcário em pomar de laranjeira Pêra em pordução. Revista Brasileira de Fruticultura, Jaboticabal, v. 29, n. 3, p. 606-612, 2007.

SOUZA, H. A.; NATALE, W.; PRADO, R. M.; ROZANE, D. E.; ROMUALDO, L. M.; HERNANDES, A. Efeito da calagem sobre o crescimento de goiabeiras. Revista Ceres, Lavras, v. 56, n. 3 , p. $336-341,2009$. 